\title{
The Actual Diagnosis and Rational Appeal of College Network Courses
}

\author{
Pan Jixin \\ Modern Educational Technology Center \\ North China Institute of Science and Technology \\ Yanjiao, China, 15350719831 \\ pjx20070310@163.com
}

Guo Fuping

Modern Educational Technology Center

North China Institute of Science and Technology

Yanjiao, China

\author{
Cheng Lulu \\ College of Foreign Languages \\ Shenyang Normal University \\ Liaoning, China
}

\author{
Liu Liping \\ Editorial Department of Journal \\ North China Institute of Science and Technology \\ Yanjiao, China
}

\begin{abstract}
Nowadays, people have wrong conclusions and unreasonable concepts about the essential attribute in college network courses. These can be illustrated by the following aspects: such as in the value, the fixed position is not conformity with expectation; in teaching, the current teaching situation is deviated from teaching expectancy. As a result, people lead to a situation where their speculation is deviated from expectancy, and construction has little to do with management, furthermore input and output imbalance. Therefore, they cannot keep out of this situation. So the author makes an attempt to thinking deeply the critical issues in order to change the cognitive deviation and error orientation of college network courses, and makes the college network courses in accordance with the regularity and aim, such as accidental and inevitable, quantity and quality, periphery and core, decoration and high-quality goods.
\end{abstract}

Keywords-college; network courses; diagnosis; appeal

\section{INTRODUCTION}

In recent years, network courses have grown vigorously in China, such as the construction course of network courses in the new century, the developing project of network courses of further education for teachers in primary and secondary schools, the research and practice for the quality certification of network education and the construction of national excellent courses, especially since the quality certification activities of network courses organized by Ministry of Education in 2003, many universities have constructed and carried out a great deal of network courses according to their own situation and need. Although they are uneven in quality, it presents a vision of a hundred flowers blossom and a hundred schools of thought contend either in the study of theory or in the discussion of practice mode since network courses have been introduced into universities. It is generally believed that network courses have changed traditional, single and obsolete idea, means and mode of education, made true of the organic combination of information skill and courses, excited the study interest of students, activated classroom atmosphere and improved the quality of education. But this is not the case. Universities network courses have lost in a bed of roses because there are deviation in the cognition of the essence of network courses and misplacement between orientation and value expectation from universities, which attributed to the false expansion and froth growth. .

\section{THE ACTUAL DIAGNOSIS OF COLLEGE NETWORK COURSES}

At present, the essence cognition for network courses from colleges is lack of self-examination and carding, which attributes to the misplacement of self-orientation and selfvalue, so that the actual situation of network courses is undesirable. It is the phenomena of "one only draws a cart with his head bowing regardless of looking up at the road" that college network courses is gradually lost in a embarrassment of not to be popular. So it is very urgent to do the actual diagnosis and thinking of college network courses so as to realize its rational appeal.

\section{A. Faulting between Cognition and Orientation}

1) Making philistinism of network courses. Most of colleges build network courses as refurbished version of literal teaching material, location-changing version of books or network courseware of computer-aided instruction. They move knowledge of traditional courses onto network and apply initial design concept of teaching to the design of network courses. This method of walking old path with new shoes reappears the drawback of traditional teaching and loses the advantage of technique environment, which are characterized by using network courses platform as optional courses platform, simply regarding network courses as teachers' teaching material and students' learning material, considering network courses as traditional courses' supplement. Colleges making philistinism of network courses, on the one hand, makes it be reduced to technical goods so it doesn't exert its potential value, on the other hand, the superficiality of its essence understanding directly results in the roughness of its practice.

2) Dissimilation of network courses. Many colleges equate network courses with online training of companies or enterprises. Thus, to some extent, it becomes a snack's 
consuming culture. The aim of setting up it in colleges is cultivating talents while the aim of training in enterprises is pursuing benefit. The quality enterprises pay attention to is immediate benefit, the staff members taking training practice with skills they master in a short time and go through performance appraisal so that a developing mode of virtuous circle takes shape. If colleges take the developing mode of enterprises which is concerned about economic benefit coming from network courses, it shall distort the essence of network courses and brings about a result of quick success and instant benefit. Besides, a part of colleges aim at network courses so as to pass the higher level's inspection or evaluation, which gives rise to a phenomena of designing for designing and producting for producting.

3) Deifying network courses. As W.Doll, a representative of post-modern perspective on curriculum regards, every curriculum has its own history background and basic vocabulary, so various subjects present their richness with their unique ways. There is nothing to be said against it that a few colleges produce their characteristic discipline to network course or excellent course. But many colleges produce all courses to network courses regardless of the characteristic of courses and discipline, magnifying its advantage and taking its application as the panacea of solving any teaching problems. Moreover, a few colleges deify network courses. They control its use and manage it strictly on campus, make it to be patent and charge for it off campus, teachers dare not to use it and students can not learn it. All these betray network's original intention and deviate network courses’ essence.

\section{B. Building and Management Being out of Joint}

1) Be industrious bout building but not good at management

In the early days of Network courses introduced in colleges, the scene of public courses has cut a figure in press's view. It is all believed that network course is the commanding height of modern course's reform. Furthermore, it is encouraged and supported by national policies. So a lot of colleges have joined in the great tide of network courses construction and produced a fair number of ones. However, there always arise problems of over-duplicated building, low level of usage rate and formatting courses' setting because of sequence of building, difference of professional standard, being lack of communication in the process of courses' construction so as to not able to learn from lessons. Meanwhile, network courses have piled up like mountains and it's very hard to practice on account of the lack of understanding for network courses and scientific management concept and methods. Network course is just like a wild horse which you couldn't tame but let it run.

\section{2) Meaningless construction but uncared-for management}

Over several years' cracking up, network courses gradually fade away from colleges. Many colleges do not blindly chase it any more with being aware of its advantages and disadvantages. There is no original passion and preference in particular any more. It doesn't matter to build it or not, only for dealing with the inspection of Ministry of Education which aims at appraisal or checking before acceptance. Thus, it results in meaningless construction and being weary. Furthermore, there is no institutional environment in which network courses develop sound, lack of scientific, reasonable and effective supervisory system, and also no ready-made management method and experience. So a majority of network platforms are still in their natural state and in a wild management mode, they can't be updated in time and get later maintenance but leave them as they are.

\section{3) Promising construction but the limit of management}

With the raise of construction principle of famous college, teacher and courses, the building of network courses has been increasingly meticulous and normative. Colleges have built characteristic network courses or excellent courses with the concentration of superior resources, had their own resource database of network courses and excellent courses' websites, and meanwhile perfected management system and certification system so as to shape favorable management environment. However, network courses that seem like accomplish something actually can't attempt anything and accomplish nothing. Because the problem is that a part of colleges are limited to management, tied to stated process and standard, can't do anything about deeper management such as the guidance of students' network study and the possession of belongingness of network space. What is called "act to greatly work well, then do consistently insistence, actually a promising man; knowing it well in mind and do nothing just in vain, this is making a futile effort". Colleges' network courses should bring the helplessness management into force in making a difference of construction.

\section{Imbalance in the Ratio of Input and Output}

Most of colleges have put a mass of manpower, material and financial resources in the building of network courses, either recruiting educational technology experts to design and technicians to develop, or building a network courses develop team combined with teaching staff, researchers and technicians. It should increase budget in the building of teaching platform of network courses, the choice, produce and purchase of course resources, the guidance learning of courses' content, the use of course platform, the setting of teaching plan and teaching period, the training of teachers and students. For example, network teaching researchers from European countries like America and England have summarized the eight roles played by network teachers, which are designers, content improvers, process drivers, scholastic assessors, counseling tutors, organization managers, learning researchers and technology supporters, on the subject seminar of Network Teacher's Ability and Quality in June 2000. The diversification of network teachers' role makes it to improve teachers' quality, increase teachers' training cost. Meanwhile, the use of network courses and the need of social development determine the standard and quality of talents, raises higher requirements for students as well. However, the use of network courses heightens cost but brings no corresponding results, increases the work of departments but gets no approval, reduces teachers' time for rest but achieves no desired teaching effect, shortens students' after-school time but raises learning task and control. In a word, it is hard to be guaranteed that colleges teaching quality counts on network courses, teachers and students cannot find their own way while 
traveling in network courses. So in the designing and using of network courses, the elements that should be taken fully into account not only include society's demand of talents, but also contain the expansion of course concept and teaching design thoughts, the change of teaching modes and methods, the age, gender, race and native language of students and teachers, so that colleges can analyze comprehensively and balance the ratio of input and output.

\section{THE ACTUAL THINKING OF COLLEGES NETWORK COURSES}

The development of colleges' network courses from actual embarrassment to rational ideal state depends on clear understanding and clarification on some key problems.

\section{A. The Emergence of Network Courses Is Accidental or Inevitable}

The generation of network courses has certain subjective elements and objective function. On the one hand, teaching connotation and extension continually expanding changes teaching modes and methods, from original word of mouth, traditional classroom teaching, to programmed instruction and computer aided instruction, then to modern distance education. Courses' research field and category are gradually richer with the input of active elements and raise new life. On the other hand, with the updating of social culture and the innovation of technology, the culture affiliated with network is doomed to integrate into current social culture, then infiltrates into education spontaneously so that courses are sure to produce innovation. With the exponential growth of knowledge and the contraction of update circle, courses are bound to be open from close, namely from the all-closed teaching of traditional courses, to the semi-closed programmed instruction, then to the network distance education. Besides, the interpersonal communication of traditional classroom teaching is made between teachers and students, which is not enough and nonequivalent as for teachers and students. While network courses breaks the indirection of interpersonal communication by tending to indirection or even diversification. This is the inevitable choice of communication and the necessary condition of the production of network courses. Contingency is the forms of expression and supplement of necessity, while necessity is present in contingency and brazes a trail by going through contingency. Therefore, it can be said that network courses is inevitable outcome gradually separated from courses that have developed a certain phrase.

\section{B. The Development of Network Courses Is Quantitative Change or Qualitative Change}

University courses' changes in recent years are as follows: content updating and quantity increase, multidisciplinary courses integrating one another, the ratio of general courses gradually recovering, attaching importance to basic synthesis of reality field and meta-study of discipline and highlighting the diversification of assessment, as well as contradiction between professional and comprehensive, prescriptive and selective, academic and practical. In other words, colleges' courses have gradually changed into complicated social activities from unsophisticated academic activities [1]. Many scholars regard network courses as reproduction and re- creation of network culture and social culture. Reproduction and re-creation is the change from "natural man" to "social man" [2]. Colleges will not exist in the form of fixed construction in the future. Network courses will not be ordinary courses, which is marked by that its forms of expression will become electrical books from paperbound books, the design thoughts of teaching software will develop into integrable ware from courseware and the backdrop will become curtain from blackboard, then to electrical whiteboard. With the popularization of higher education, especially the change of university group, its internal differences and the diversification brought about by the demand of the change, "courses problem cannot still be hidden in ivory tower and it should be discussed together and decided by people from all fields” [3]. Thereby, network courses will move forward undoubtedly with periodical qualitative change while various contradictions existing in network courses will tolerate mutually and coordinate with one another in a relatively stable period, which will be basic state of network courses, namely extremes of quantitative change, which will gradually transit into qualitative state with the accumulation of quantity.

\section{Network Courses Will Be Edge or Core}

Our country's higher education is mainly about professional education in the long process of development. The whole education plan is arranged mainly around professional and emphasizes the systematicness and integrity of disciplines in curriculum setting. Hence, colleges has always regarded network courses as the supplement of traditional courses, plus colleges leadership have paid little attention to it and publicized insufficiently, network courses has been all along dispensable. Network courses still hover at the edge of courses though it plays key role in the teacher training, adult education and in-service study. Besides, learners prefer traveling in paperbound books to browsing in network courses on account of the differences of cognitive characteristics and study habits. Nevertheless, with the continuous extension of courses content, universities gradually get over liberal education that deviates from real society, move towards opening education that is helpful for problem solving, lay stress on the combination of general courses and professional courses, common education and vocational education, and network courses nicely meets society's demand and the need of the change and development of universities. The core of network courses is autonomic learning, which strengthens the active of learning but weakens the process of teaching, and is beneficial to ubiquitous learning and inclusive education. The survey result done by Sloan Consortium, which is sponsored by Alfred P. Sloan Foundation, a non-profit organization, presents that universities network courses will counterbalance with traditional courses very soon [4]. As the saying goes, "Seeds are in the present, fruit is in the future". It is temporary for network courses being at the fringe of courses and it will be the core in the end as long as it gets reasonable use and gives play its own strong points.

\section{Network Courses Is a Decoration or a Boutique}

Some universities pay more attention to the external form of network courses. They make its web structure orderly, its interfacial layout novel, color collocation brilliant and give learners excitement of their senses with 
the various form of expression of video, audio, texts and flash. Though the attention and emotion of students are attracted by colors and special effects, their cognitive thinking are easily neglected, so the knowledge students can learn is hard to measure and grasp, which cannot help but make people think of the stubborn illness of China's enterprise training, which is exciting in class, moved after class, a little impulsive at work and motionless in the end. Are network courses the same as enterprise training, which give learners a transient billow in mind and no action and practical effect? Other universities regard network courses as a brand effect only for keeping up appearances and charge for logging in, which protects intellectual property but limits knowledge dissemination and resource sharing so that network courses is reduced to decoration at last. Therefore, some people rethink that how much benefit we can get from web-based instruction under its ornate appearance. Who is the flower of online education that gets so much praise charming for? We should make network courses become a carrier of new courses, not a fetter and an affectedly unconventional decoration that reverses the position of the host and the guest, because flowers can only be charming for vanity and feel sorry for themselves even if they are beautiful enough [5]. Network courses, especially excellent courses, concentrating superior education resources and following the construction principles of famous teachers, colleges and courses, definitely belongs to boutique. But it will be waste if it stays unused or is used in the wrong place.

\section{THE RATIONAL APPEAL OF COLLEGES NETWORK COURSES}

\section{A. Network Course Is the Sublimation of Course}

Network course is neither simply adding modifier in front of courses nor the summation of courses and network, yet an independent total concept. Traditional course is linear and has the brand of Taylor Principle, while network course has the mesh topology with knowledge nodes linking. Network courses had exceeded the content of traditional course, broken through the limit of its own and extended into product of social demand and culture replacement. Just as Nicholas Negroponte says, computing decides our existence and is not relevant to computer anymore [6]. So, though network course includes the characteristic of network and courses in function, it is no longer only relating to network and courses. Problems needed to discuss in all courses will be endowed with new significance in network condition. Network course is not only the integration of network in technological concept and courses in educational concept, but also the combination of network and courses both in cultural concept [7]. Network course is the sublimation of course, which are mainly as following: changing courses' content in quality, breaking through the limit of time and space, embodying the equality of education opportunity and the balance of education resources, reducing human nature and the flexibility of expression, achieving the transformation of technological products to social culture, enriching the selectivity of knowledge and the autonomy of learning, highlighting some properties of courses, demonstrating its own characteristic and forming independent study field. Just as H. Taba, a curriculum expert says, education basically is a process of evolution, it grows gradually, takes root among history and points to future, which is also a process of organism in this sense.

\section{B. Network Course Embodies Learning Ubiquity}

Network course breaks through the limit of time and space of traditional course, achieves the integration of physical and information space and changes the connotation and extension of learning, which the most outstanding expression among is learning ubiquity: (1) ubiquity of learning object. On the one hand, the object of network courses is not only undergraduates but also all learners needed to receive network education, on the other hand, the space distribution of learners is wide and they can study at any space connecting network. (2) ubiquity of learning interaction. The interaction in the learning of network courses not only contains the interaction of teachers and students, students and students but also the interaction of learners, technological products and social environment. (3) ubiquity of learning resources. Ubiquitous learning resources make learners immerge themselves into network, get right information by proper means in appropriate places and ensure that helpful knowledge is passed on to people in need. (4) ubiquity of learning supporting service. The interface, navigation design, information structure and language expression of network courses meet psychological rules. It doesn't increase the cognitive burden of learners, make learners concentrate their perception and thoughts in study task itself, provide services for learners all the time with neglecting the exist of network. (5) ubiquity of learning management. Learners can control or delete their own study progress and real-time record, accomplish the integration of plan, organization, leadership, controlling and innovation management, embody the diversity of performance, project, resources and program efficiently, evaluate and supervise the whole process with various means combined.

\section{Network Course Provides the Inclusion of Education Elements}

Network courses seemingly belongs to school education, but it exceeds the content of narrow education and reaches the category of broad education from deeper understanding despite the main aim of setting up network courses is degree education and further education. Therefore, college network courses provide possibility for inclusive education and braze a trail for the inclusion of education elements. First, it embodies in educators. It's neither one to many nor one to one but many to one on the ratio of teachers and students. Teachers appear in collective concept; there are companions, tutors, experts and international scholars on quality level, there are teachers of the subject, interdisciplinary and cross disciplinary on structure. Then, it embodies in the educated. The object of network courses has been orientated either intentionally or accidentally with people of normal body and mind, who have mainstream network equipment and higher computer skills, while disabled people, people with low information skill and no mainstream network equipment are marginalized, even normal learners are blocked by barriers at home and abroad [8]. Superior network courses should be oriented to all learners and increases education opportunities for 
those deprived of education chances on account of various reasons. Last, it embodies in process elements. It includes not only education environment and contents but also teaching means and learning methods, almost embracing all elements of the whole education process. Higher education moves towards general education from liberal education then to inclusive education. Liberal education is established in upbringing idea of individual liberation and lays stress on value of nurturing your mind [9]; general education focuses on cultivating not teaching and its aim is to foster perfect person; inclusive education regards courses should adapt to students not students adapt to courses.

\section{Network Courses Is Aim at Achieving the Optimization of Resources Integration}

The original appeal of network courses is to make students self-directed learning anytime, anywhere and accomplish the purpose of education through network while the final appeal is to achieve the optimization of resources integration. Ministry of Education has started successively and implemented various building project of network courses, aiming at promoting the sharing of high quality teaching resources and alleviating the actual state of shortage of teaching resources in the background of mass higher education. At the macro, resources integration not only includes the integration of network teaching thoughts and courses ideas, of teaching modes and learning methods, of teaching programs and learning styles, but also the integration of social culture and technological environment. Thus, network course is the organic integration of curriculum rationale, technological environment and social culture. While resources integration is mainly about the integration of courses elements on the analysis of microcosm. Firstly, it's the integration of quality and richness. "One can't make brick without straw". The successful design of network course depends on the coordinating level of the quality and richness of elements. Secondly, it's the integration of different elements. The layout of pictures and texts is helpful not only for learners paying their attention to the important points but also for them understanding and memorizing key concepts [10]. Thirdly, it's the internal integration of elements. Study on psychology shows that the hold time of attention in the learning process is relevant to the content of learning material and the change, colors of material as well. So, it requires optimized integration of content elements and resource environment so as to achieve the maximization of functions based on network concept and teaching theory if we want to realize the resource integration of network courses.

\section{CONCLUSION}

Actuality is the existence condition of things in real society and is inherent in ration, while ration manifests its own value by means of the rethink and exceeding of actuality. The transformation from actuality to ration requires many conditions, without which they will be divorced even deviated from each other. Hence, we must clearly recognize that the rational appeal of network courses can't be accomplished at one stroke but requires a complicated and slow developing process. Only facing up to the actual diagnosis of network courses can we achieve the approach and transformation of actuality and ration so as to reach the ideal state of ration. Therefore, it should become new study context of researchers and mutual value pursuit that how to realize the transformation of college network courses from actuality to ration.

\section{REFERENCES}

[1] Xie Weihe(2005). Changes and features of curriculum for universities and colleges[J]. Educational Research(in chinese), (2): 68-70.

[2] Sang Xinmin(1993). Call for the educational philosophy of new century[M].Beijing:Educational Science Publishing House(in chinese).

[3] Philip G. Altbach, Robert O. Berdahl, and Patricia J. Gumport(2005). American higher education in the twenty-first century-social, political, and economic challenges[M]. Beijing: Beijing Normal University Press(in chinese).

[4] Gao Zhi(2011). Why the network courses of domestic colleges do not fare exceedingly well[J]. Education and Vocation(in chinese), (19): 90.

[5] Jiang Hualing, Qu Yuping(2005). Network courses: for whom the charming?[N].China Education Daily(in chinese).

[6] Negroponte(1997). Being digital[M]. Translated by Hu Yong and Fan Haiyan. Haikou:HaiNan Press(in chinese).

[7] Zhao Jian(2007). A study on web-based curriculum[D]. Chengdou: Southwest University(in chinese).

[8] Huang Lu,Sun Zhenxiang, Wang Manhua(2007). Core Problems of Accessible Web Course[J]. China Educational Technology(in chinese), (10): 53-55.

[9] Sato Manabu(2003), Curriculum and teachers[M]. Translated by Zhong Qiquan. Beijing: Educational Science Publishing House(in chinese).

[10] Januszewki Alan, Molenda Michael(2010). Educational technology: a definition with commentary[M]. Translated by Cheng Dongyuan, Wang Xiaoxue and Liu Yongqian. Beijing: Peking University Press(in chinese). 